\title{
Development of Knowledge, Attitude and Practice Questionnaire of Parents towards Vaccination: Process, Challenges and Solutions
}

\author{
Juny Sebastian', Gurumurthy Parthasarathi ${ }^{1 *}$, Mandyam Dhati Ravi ${ }^{2}$ \\ ${ }^{1}$ Department of Pharmacy Practice, JSS College of Pharmacy, Jagadguru Shri Shivarathreeshwara University, Mysuru, Karnataka, \\ INDIA \\ ${ }^{2}$ Department of Pediatrics, JSS Medical College and Hospital, Jagadguru Shri Shivarathreeshwara University, Mysuru, Karnataka, \\ INDIA
}

\begin{abstract}
Objectives: This study aimed to develop and validate a questionnaire to observe the knowledge, attitude and practice of parents towards vaccination. Methods: The questionnaire was developed based on an extensive literature review and experts' opinion. The questionnaire was then subjected for validation and translated to the local vernacular from English. Cronbach's alpha and Sperman's rank coefficient was used to estimate the internal consistency of the questions in the questionnaire and test -retest reliability of the questionnaire respectively. Results: The overall content validity score and the item content validity index (I-CVI) of the prepared questionnaire was 3.83 and $95.5 \%$ respectively. The internal consistency of the questionnaire measured using Cronbach'salpha was found 0.89 . The mean + standard deviation of the KAP scores for test group and retest group was 37.5 +6.53 and $37.9+6.063$ respectively. The calculated Sperman's rank correlation coefficient value was 0.957 $(p<0.001)$. Conclusion: The questionnaire is acceptable and the relevance was high among all the four parameters $(97 \%)$ of the content validity index. The prepared questionnaire showed high reliability and stability between KAP scores of the test and retest. The Kannada questionnaire is simple and easy to use but the time taken to complete the questionnaire is a limitation of the study.
\end{abstract}

Key words: Knowledge, Attitude and Practice (KAP), Content Validity, Validation of Questionnaire, Immunization.

\section{INTRODUCTION}

After the introduction of Expanded Program on Immunization by World Health Organization (WHO) in 1974, global coverage with routine vaccines has increased from $<5 \%$ to $\geq 84 \%$, coverage of the third dose of diphtheria-tetanus-pertussis vaccine [DTP] by the end of 12 months of age is a major indicator of immunization program performance. ${ }^{1}$ There are 160 countries reached 80\% and 129 counties reached $90 \%$ coverage with DTP3 containing vaccine in $2013 .^{2}$ Among the 21.8 million children who did not receive DTP 3 dose series during 12 months of life, 10.9 million (50\%) lived in three countries (India [31\%], Nigeria [13\%] and Pakistan [6\%]). ${ }^{1}$ Priority needs to be given to strengthening rou- tine vaccination globally, especially in the countries that are home to the highest number of unvaccinated children. Particular efforts are needed to reach the underserved, especially those in remote areas, in deprived urban settings, in fragile states and regions in India. ${ }^{3}$

One of the major barriers for less immunization coverage in India are huge population with relatively high growth rate. Lack of awareness is another great barrier for non-immunization or partial immunization. Other barriers unique to India and making the comlpete vaccination coverage task more complex are geographical diversity (snow bound/ hilly areas, deserts, tropical forest areas, remote island territories), cultural diver-
DOI: 10.5530/ijopp.10.2.23

Address for correspondence: Dr. G Parthasarathi, Professor, Department of Pharmacy Practice, JSS College of Pharmacy, Jagadguru Shri Shivarathreeshwara University, Mysuru, Karnataka, INDIA

Phone no: 9845659585 E-mail: gparthasarathi@jssuni. edu.in 
sity (with various religions, languages, traditions, beliefs and customs) and political instability ("coalition" governments, "politically sensitive areas" like Naxal/terrorist-affected areas). Wide coverage of sdverse events following immunization (AEFI) news in medias, even when the reactions are unrelated to vaccine administration also have contributed for the decreased coverage of vaccines among certain communities. The other reasons include inadequate delivery of health services (supply shortages, vacant staff positions, and lack of training); lack of accountability, inadequate supervision and monitoring; lack of micro- planning at district level; general lack of inter-sectoral coordination and lack of coordination between state and central governments resulting in missed opportunities to improve immunization coverage and quality. Falsification and over-reporting of vaccine coverage rates are other big concerns as they give false sense of security and interfere with proper planning. To overcome all these barriers, it is very important to increae the awareness about the vaccination among the public and heath care professionals. ${ }^{4}$

According to the national family health servey 4 (2015-16), the percentage of children fully vaccinated between the age group of 12 to 23 months are only $55 \%$ in Karnataka. ${ }^{6}$ Vaccine hesitancy of the parents has been increased due to their own concerns about vaccine and AEFIs and antivaccine movement is encouraging them to refuse vaccination for their children. Unfortunately the refusal of parents may have been shown to increase the risk of vaccine preventable diseases and decrease the herd immnuty. ${ }^{5}$ As parents are the primary decision makers about the vaccination coverage, their knowlde, attitude and practice (KAP) has a great impact on the immunization status of their children. The conflicting media reports about vaccine safety and the anti-vaccine lobby activitieas can highly influence the decision making process among the parents. Thus it is vital to assess the KAP of parents towards children vaccination in order to increase the vaccination coverage. ${ }^{7}$

A validated tool is required to aseesss the KAP of parents towards vaccination. Measuring the content validity helps to ensure the construct validity and give confidence among the researchers about the tool they use to assess the KAP. Content validity measures the representativeness and the comprehensiveness of the content of the prepared tool. ${ }^{8}$ Researchers provide evidence for content validity by computing item content validity index (I-CVI) and scale content validity index(S-CVI). I-CVI informa- tion helps to revise, delete or substitute items to the tool under validation. S-CVI is the content validity of the overall scale. ${ }^{9}$

The study objective was to create and validate a questionnaire that assesses knowledge, attitude and practice of parents towards the immunization.

\section{METHODS}

\section{Development of questionnaire}

The questionnaire was developed after an extensive literature search using the following key wordsknowledge, attitude and practice questionnaire, KAP study, KAP of parents on vaccination, validation of questionnaire, content validity index using the search engines like google scholar, science direct, pubmed/medline and clinical key. The questionnaire was developed in English initially to maintain the consistency from published literatures.-10-24 Additional questions were added to cover the objectives of the study. To finalise the questionnaire, there was a detailed discussion among the researchers (the authors). The developed questionnaire was limited to 25 questions that was considered feasible and focused on knowledge, attitude and practice of parents about the vaccines in the national expanded program on immunization program (EPI) and 5 questions on non-EPI vaccines commonly used in practice. EPI section of the questionnaire consisted of 15 questionsregading knowledge, 5 questionsregardingattitudes and the remaining 5 questions regardingthe practice of parents towards immunization. There were two questions assessing the knowledge, one and two question each assessing the attitude and practice in the non- EPI vaccines section. Language correction of the questionnaire was done by an English language expert (Annexure available online).

\section{Validation of the questionnaire}

The final questionnaire was subjected for the content validity index (CVI) with the help of a four point criteria for measuring the CVI. ${ }^{8}$ Each question in the questionnaire was subjected for the content validity by thirty experts in related fields (Pediatrics, Pharmacy, Nursing and Social work) and included the faculty from all different cadres, staff and final year students of the respective departments. The researcher gave a copy of the questionnaire with the criteria for CVI and explained the purpose and the objective of the study individually to all experts. The experts were asked to rate each question and answer based on relevance, clarity, simplicity and ambiguity on the four point scale. The Content 
validity index of the scale (S-CVI) was also measured based on the rating by the experts. ${ }^{8,9-19}$ The statistical analysis was done using Microsoft Excel and the Statistical Package for Social Science (SPSS) version 22 for windows. Cronbach's alpha was used to estimate the internal consistency/ reliability of the questions in the questionnaire. ${ }^{19}$

\section{Translation}

The questionnaire was translated to the local vernacular language (Kannada) with an expert from the Central Institute of Indian languages (CIIL) located in Mysore. Following translation from English to Kannada, it was reviewed by a bilingual health care professional. Next, a back translation of the Kannada questionnaire to English was done by another similar expert.. This too was reviewed to ensure accuracy of the questionnaire.

Following ethical committee approval of the study, the questionnaire was distributed among 10 parents to collect a feedback on easiness in understanding the questions, practicability of the questions asked and to comment on the time taken to complete the questionnaire.

\section{Test- retest reliability}

Test - retest reliability was conducted to assess the internal consistency of the questionnaire among subgroup of 10 parents whose babies aged between two to five years. A retest was done on the same group after four weeks of the initial administration. ${ }^{7,11}$ Mean and standard deviation was calculated for the total knowledge, attitude and practice scores and scor-

Table 1: I-CVI Scores of the questionnaire

\begin{tabular}{|c|c|c|c|c|c|c|}
\hline Question Numbers & Relevance Score & Clarity Score & Simplicity Score & Ambiguity Score & Average Score & I-CVI (\%) \\
\hline Q 1 & 4.0 & 3.9 & 4.0 & 4.0 & 3.97 & 99.25 \\
\hline Q 2 & 3.93 & 3.86 & 3.9 & 3.9 & 3.89 & 97.25 \\
\hline Q 3 & 3.96 & 3.86 & 3.9 & 3.9 & 3.9 & 97.5 \\
\hline Q 4 & 3.8 & 3.83 & 3.8 & 3.8 & 3.85 & 96.25 \\
\hline Q 5 & 3.93 & 3.86 & 3.8 & 3.93 & 3.84 & 96 \\
\hline Q 6 & 3.93 & 3.9 & 3.93 & 3.93 & 3.91 & 97.75 \\
\hline Q 7 & 3.96 & 3.9 & 3.93 & 3.93 & 3.93 & 98.25 \\
\hline Q 8 & 3.9 & 3.93 & 3.83 & 3.83 & 3.82 & 95.5 \\
\hline Q 9 & 3.93 & 3.83 & 3.9 & 3.9 & 3.89 & 97.25 \\
\hline Q 10 & 3.8 & 3.76 & 3.63 & 3.63 & 3.7 & 92.5 \\
\hline Q 11 & 3.83 & 3.82 & 3.73 & 3.73 & 3.77 & 94.25 \\
\hline Q 12 & 3.86 & 3.82 & 3.73 & 3.73 & 3.78 & 94.5 \\
\hline Q 13 & 3.8 & 3.81 & 3.76 & 3.76 & 3.78 & 94.5 \\
\hline Q 14 & 3.7 & 3.81 & 3.73 & 3.73 & 3.74 & 93.5 \\
\hline Q 15 & 3.76 & 3.8 & 3.6 & 3.6 & 3.69 & 92.25 \\
\hline Q 16 & 3.93 & 3.8 & 3.8 & 3.8 & 3.83 & 95.75 \\
\hline Q 17 & 3.96 & 3.79 & 3.96 & 3.96 & 3.91 & 97.75 \\
\hline Q 18 & 3.86 & 3.79 & 3.73 & 3.73 & 3.77 & 94.25 \\
\hline Q 19 & 3.83 & 3.78 & 3.73 & 3.73 & 3.76 & 94 \\
\hline Q 20 & 4.0 & 3.77 & 3.9 & 3.9 & 3.89 & 97.25 \\
\hline Q 21 & 3.93 & 3.77 & 3.86 & 3.86 & 3.85 & 96.25 \\
\hline Q 22 & 3.93 & 3.76 & 4.0 & 4.0 & 3.92 & 98 \\
\hline Q 23 & 3.93 & 3.76 & 3.8 & 3.8 & 3.82 & 95.5 \\
\hline Q 24 & 3.76 & 3.75 & 3.93 & 3.93 & 3.84 & 96 \\
\hline Q 25 & 3.76 & 3.75 & 3.83 & 3.83 & 3.76 & 94 \\
\hline Q 26 & 3.9 & 3.74 & 3.96 & 3.96 & 3.89 & 97.25 \\
\hline Q 27 & 3.9 & 3.74 & 3.93 & 3.93 & 3.82 & 95.5 \\
\hline Q 28 & 3.9 & 3.74 & 3.93 & 3.93 & 3.87 & 96.75 \\
\hline Q 29 & 3.83 & 3.72 & 3.86 & 3.86 & 3.81 & 95.25 \\
\hline Q 30 & 3.9 & 3.83 & 3.86 & 3.86 & 3.86 & 96.5 \\
\hline
\end{tabular}


ing awarded was a point for each correct and zero for each incorrect answer. A Spearman's rank coefficient was then calculated to investigate the testretest reliability of the questionnaire. ${ }^{7-19}$

\section{RESULTS}

\section{Questionnaire preparation and validation}

All identified CVI experts (30) submitted their responses, but some only after frequent reminders/ interventions. This included telephonic call, emails, messages, and even personal visits for submission of CVI scores. Some of the experts (40\%) completed the validation of the questionnaire by the second intervention and a $13.33 \%$ of experts required 4 interventions to respond to the validation of the questionnaire.

The experts had scored each question for the relevance, clarity, simplicity and ambiguity (Table 1 ). The overall content validity score and the I-CVI of the prepared questionnaire was 3.83 and $95.5 \%$ respectively. Relevance was high among all the parameters $(97 \%)$ in the scale content validity index(S-CVI) (Figure 1).

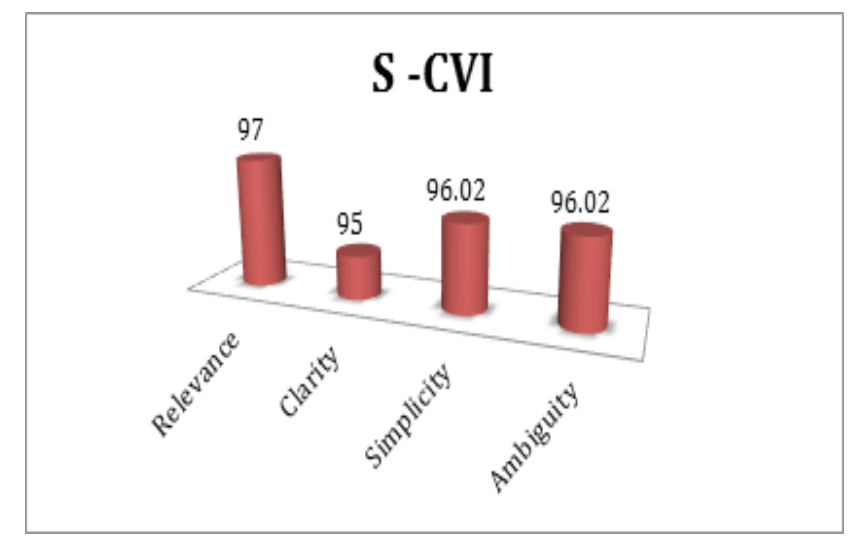

Figure 1: S-CVI Scores.

The internal consistency of the questionnaire was measured using Cronbach's alpha and was found that as 0.89 and the details are present in Table 2

Test- retest reliability

Table 2: Internal consistency of the questionnaire.

$\begin{array}{ccc}\text { SI No } & \text { Parameters } & \text { Cronbach's Alpha } \\ 1 & \text { Relevance } & 0.87 \\ 2 & \text { Clarity } & 0.917 \\ 3 & \text { Simplicity } & 0.903 \\ 4 & \text { Ambiguity } & 0.87 \\ & \text { All together } & 0.89\end{array}$

The mean + standard deviation of the KAP scores for test group and retest group enrolled for the test -retest reliability was $37.5 \pm 6.53$ and $37.9 \pm 6.063$ respectively. The calculated Sperman's rank correlation coefficient value was $0.957(\mathrm{p}<0.001)$.

\section{DISCUSSION}

Understanding the validity (CVI) of the newly developed tool is important for researchers to realize that the instrument they use for the study is suitable for the construct, population and socio- cultural background of the region under study. The questionnaire of KAP of parents towards immunization developed in this study had acceptable indices of a standard questionnaire. Percentage higher than $80 \%$ for I-CVI and S-CVI is considered as minimum acceptable rate for a newly prepared tool., ${ }^{9}$ No questions were discarded as all the questions scored I-CVI of more than 0.75 but few questions were modified based on the opinion from the experts. ${ }^{8}$ All the questions in the developed questionnaire scored percentages more than $92 \%$, so the prepared questionnaire can be used to assess the KAP of the parents among the local population targeted for the KAP study. Internal consistency was also better for the domains of knowledge, attitude and practice of parents towards immunization as it exceeded the minimum score of 0.70 .

There were no specific comments, which lead to the review of the questionnaire by parents. The parents opined that Kannada questionnaire was simple, easy to use but it takes minimum ten minutes to complete. Sperman's rank correlation coefficient score was high, indicating a satisfactory reliability and stability between the test and retest groups. It appears to be a reliable tool to measure objectively the knowledge, attitude and practice of parents towards immunization in the local community.

\section{Challenges and its solutions}

Developing questions applicable to local population was the first challenge as there was less number of published literatures covering all aspects of vaccination including questions related to the adverse events following Immunization (AEFI) in the local population of Karnataka. Developing questionnaire which doesn't affect the socio-regional feelings of the society was the next challenge. The questionnaire was prepared after consultation with the experts like pediatricians, immunization center nurse, pharmacists, social workers and few parents to overcome these challenges

Indian Journal of Pharmacy Practice, Vol 10, Issue 2, Apr-Jun, 2017 
Collecting the validated questionnaire from the experts was also a challenge as all of them were from different health care background and of different cadres. This was overcome by frequent interventions like telephone calls, emails, messages and personal visits. Translation of English questionnaire to locally applicable Kannada questionnaire was also a challenge as there is a regional variation in the Kannada language. Continuous interaction with the language expert helped to come out with a locally applicable questionnaire.

\section{CONCLUSION}

The KAP questionnaire was prepared after an extensive literature search and was subjected for CVI and it possess satisfactory reliability and a good internal consistency. The challenges were overcome by expert opinion from a wide range of profession directly or indirectly related to vaccination process and frequent interaction with them. The questionnaire appeared to be a reliable tool to measure objectively the knowledge, attitude and practice of parents towards immunization in the local community.

\section{LIMITATION}

The major limitation identified after the validation process is the time required for the parents to complete the questionnaire.

\section{ACKNOWLEDGEMENTS}

The authors would like to thank health care providers helped for the validation of the questionnaire and also the parents who agreed to participate in this study. We also acknowledge the contribution of Dr. Sanjiv Lewin, Professor and Head, Department of Pediatrics, St. John's Medical College, Bengaluru for his efforts in correcting the draft manuscript.

\section{FUNDING SOURCE}

This research received no specific grant from any funding agency in the public, commercial or notfor-profit sectors.

\section{CONFLICT OF INTEREST}

\section{None}

\section{ABBREVIATION USED}

I-CVI: item content validity index; KAP: Knowledge; Attitude and Practice; WHO: World Health
Organization; DTP: Diphtheria-tetanus-pertusis; AEFI: Adverse events following immunization, S-CVI: scale content validity index; CVI: Content validity index; EPI: Expanded program on immunization; SPSS: Statistical package for social science; CIIL: Central institute of Indian Languages.

\section{REFERENCES}

1. Harris JB, Gacic-Dobo M, Eggers R, Brown DW, Sodha SV, Centers for Disease Control and Prevention (CDC). Global routine vaccination coverage, 2013. MMWR Morb Mortal Wkly Rep. 2014;63(46):1055-8. Available from http://www. cdc.gov/mmwr/preview/mmwrhtml/mm6346a4.htm. Accessed August 252015

2. WHO/UNICEF coverage estimates 2013 revision, July 2014, available from: http://apps.who.int/immunization_monitoring/globalsummary/timeseries/ tswucoveragebc g.html. Accessed August 2015

3. Immunization coverage fact sheet 2014. Available from http://www.who.int/ mediacentre/factsheets/fs378/en/. Accessed May 102015

4. VM Vashishtha, P Kumar. 50 years of Immunization in India: Progress and Future. Indian Pediatrics 2013;50:111-8

5. Smith PJ, Humiston SG, Marcuse EK, Zhao Z, Dorell CG, Howes C, et al. Parental delay or refusal of vaccine doses, childhood vaccination coverage at 24 months of age, and the Health Belief Model. Public health reports. 2011;126(2_suppl):135-46.

6. National family health survey $4(2015-16)$, India. Database that strengthen India's demographic and health policies and programmes. Available from http://rchiips.org/nfhs/nfhs4.shtml. Accessed September 2016.

7. Awadh AI, Hassali MA, Al-lela OQ, Bux SH, Elkalmi RM, Hadi H. Immunization knowledge and practice among Malaysian parents: a questionnaire development and pilot-testing. BMC public health. 2014;14(1):1107.

8. YaghmaieF. Content validity and its estimation. Journal of medical education 2003;1(1):25-7

9. Denise F. Polit,Cheryl TatanoBeck. The Content Validity Index: Are You Sure You Know What's Being Reported? Critique and Recommendations. Research in Nursing \& Health. 2006;29:489-97.

10. Al-Lela OQ, Bahari MB, AI-Qazaz HK, Salih MR, Jamshed SQ, Elkalmi RM. Are parents' knowledge and practice regarding immunization related to pediatrics' immunization compliance? a mixed method study. BMC pediatrics. 2014;14(1):20.

11. Al-lela QOB, Bahari MB, Al-abbassi MG, Basher AY. Development of a questionnaire on knowledge, attitude and practice about immunization among Iraqi parents. J Public Health. 2011;9:1-7

12. Sylvia E. Caingles, Joanne J. Lobo. Development of a questionnaire on knowledge, attitude and practice about immunization among Iraqi parents. PIDSP Journal. 2011;12(1):46-52.

13. Al-lela OQB, Bahari MD, Salih RM, Al-abbassi MG, Elkalmi RM Jamshed $S Q$. Factors underlying inadequate parents' awareness regarding pediatrics immunization: findings of cross-sectional study in Mosul- Iraq. BMC Pediatrics. 2014;14(29):1-7

14. Nath B, Singh JV, Awasthi S, Bhushan V, Kumar V, Singh SK. KAP Study on Immunization of Children in a City of North India - A 30 Cluster Survey. Online J Health Allied Scs. 2008;7(1):1-6

15. Yousif M, Albarraq A, Abdallah M, Elbur A. Parents' knowledge and attitudes on childhood immunization, Taif, Saudi Arabia. J Vaccines Vaccin. 2013;5(215):2.

16. Mereena SR, Sujatha R. A study on knowledge and attitude regarding vaccines among mothers of under five children attending pediatric OPD in a selected hospital at Mangalore. IOSR J Nursing and Health Science. 2014;3(5):39-46.

17. Angadi MM, Jose AP, Udgiri R, Masali KA, Sorganvi V. A study of knowledge, attitude and practices on immunization of children in urban slums of Bijapur city, Karnataka, India. Journal of clinical and diagnostic research: JCDR. 2013;7(12):2803-6.

18. Mukherjee S, Madhivanan P, Li T, Albatineh A, Srinivas V, Jaykrishna P, Arun A, et al. Correlates of completing routine vaccination among children in Mysore, India. Journal of infection and public health. 2015;8(1):62-71.

19. Rasouli-Ghahroudi AA, Rokn AR, Khorsand A, Aghajani H, Amini A, Shamshiri $A R$, et al. Designing and standardizing a questionnaire for evaluating 
knowledge, attitude, and practice of Iranian adults with cardiovascular diseases about oral health. ARYA atherosclerosis. 2013;9(6):350-6

20. Al-Zahrani J. Knowledge, attitude and practice of parents towards childhood vaccination. Majmaah J. Health Sciences. 2013;1(1):29-38

21. Manjunath U, Pareek RP. Maternal knowledge and perceptions aboutthe routine immunization programme--a study in a semiurban area in Rajasthan. Indian journal of medical sciences. 2003;57(4):158-63.
22. Qidwai W et al. Knowledge, attitude and practice regarding immunization among family practice patients. JDUHS. 2007;1(1):15-19

23. Mabrouka A, Bofarraj M. Knowledge, attitude and practices of mothers regarding immunization of infants and preschool children at Al-Beida City, Libya 2008. Egypt J Pediatr Allergy Immunol. 2011;9(1):29-34.

24. Caingles SE, Lobo JJ. Survey on the knowledge, attitudes and practices of parents in barangay $8 \mathrm{a}$, district 1 , Davao City regarding their children's immunization. PIDSP Journal. 2011;12(1):46-52.

\section{What is already known?}

According to NFHS, the full coverage of all basic vaccination till the age of 23 months is only $43.5 \%$ in India and in Karnataka it is $55 \%$. This percentage can be increased by the interventions to the parents.

\section{What this study adds?}

The study is adding a new valid tool to assess the knowledge, attitude and practice of parents towards vaccination which helps to make measures to address the basic issues in decreased routine vaccination coverage among the local population. 